\title{
TEKNOLOGI BUOY UNTUK OBSERVASI IN-SITU PERAIRAN SEKITAR RUMPON
}

\author{
THE BUOY TECHNOLOGY FOR IN-SITU OBSERVATION OF WATER PARAMETER AROUND \\ FISH AGGREGATING DEVICE
}

\author{
Handy Chandra \\ Pusat Pengkajian dan Perekayasaan Teknologi Kelautan dan Perikanan (P3TKP) \\ Badan Penelitian dan Pengembangan KP, KKP. Jl. Pasir Putih 1, Ancol, 14430, Indonesia \\ e-mail: handavin@gmail.com
}

Diterima tanggal: 21 Juli 2014, diterima setelah perbaikan: 7 November 2014, disetujui tanggal: 2 Desember 2014

\begin{abstract}
ABSTRAK
Aplikasi pemanfaatan buoy PLUTO sudah berhasil diujikan di perairan budidaya rumput laut (Wakatobi) tahun 2010 , tambak (Pekalongan), muara pelabuhan perikanan Pekalongan dan keramba jaring apung Tuna di Wakatobi (2013). Pada tulisan ini dilakukan kajian secara teknis dan teoritis untuk ditempatkan di perairan sekitar rumpon. Paper ini mencoba menilai aspek teknologi observasi in-situ dengan memanfaatkan buoy untuk memahami relasi penangkapan ikan di sekitar rumpon dengan parameter lingkungan perairan. Menurut literatur kajian ini masih jarang dilakukan dan mungkin belum pernah dilakukan, khususnya untuk pemantauan perairan sekitar rumpon dengan data secara menerus. Hasilnya adalah buoy perlu dilengkapi dengan sensor suhu, salinitas, oksigen terlarut, keasaman, klorofil-a, dan arus. Pemasangan pada rumpon cukup diikat saja, dan tidak mengubah perilaku dan kebiasaan nelayan dalam memasang rumpon.
\end{abstract}

Kata kunci: rumpon, suhu, salinitas, oksigen terlarut, keasaman, dan klorofil-a.

\begin{abstract}
PLUTO buoy has already been tested in seaweed culture area (Wakatobi) in 2010, pond (Pekalongan), fishing port estuary in Pekalongan and Tuna sea cage in Wakatobi (2013). This paper describes technical and theoritical aspect to install buoy in waters around FAD (fish aggregating device). The technology of in-situ observation for undertanding relationship of fishing catch around FAD with water parameter measurement was assessed. According to references, this study is rarely conducted and probably never been done, especially with continuous data of measurement. Result showed that it need temperature, saliniity, $D O, p H$, chlorophyll-a and current sensors to be equipped on board. The installation of buoy is by tied it up, and do not change habits and cultures of fishermen.
\end{abstract}

Keywords: Fish Aggregating Device (FAD), temperature, salinity, DO, pH, chlorophyll-a.

\section{PENDAHULUAN}

Aplikasi pemanfaatan buoy PLUTO sudah berhasil diujikan di perairan budidaya rumput laut (Wakatobi) (Chandra, 2012), dilanjutkan dengan implementasi pada tahun 2013 di tambak (Pekalongan), muara pelabuhan perikanan Pekalongan dan keramba jaring apung Tuna (Wakatobi). Namun demikian, untuk aplikasi lainnya, masih belum dilakukan. Hal menarik jika aplikasi buoy PLUTO dicoba untuk diaplikasikan pada perairan-perairan lain.
Pada masa kini, penangkapan ikan lebih diarahkan untuk kepentingan konservasi serta penghematan energi (Purbayanto et al., 2010). Karena pertimbangan kenaikan harga bahan bakar minyak (BBM) - mulai dari Rp. 500,- pada tahun 1990-an, kemudian naik menjadi Rp. 2.500,- ; kemudian menjadi Rp.4.500,- ; lalu menjadi Rp. 6.000,- pada tahun 2012 - mengakibatkan penggunaan rumpon (FAD, fish aggregating device) semakin marak di Indonesia, dimana salah satu tujuannya adalah untuk efisiensi pemakaian solar kapal nelayan. Di Sorong (Papua Barat) pemasangan rumpon bisa menghemat pemakaian BBM sampai 50\% (Baskoro et al., 2011). 
Secara umum, rumpon menggunakan teknik pengendalian tingkah laku ikan melalui pemikatan (attraction) dan kemudian di tangkap (Purbayanto et al., 2010). Rumpon, yang dikenal secara internasional sebagai $\mathrm{FAD}$ (fish aggregating device), merupakan salah satu alat bantu penangkapan yang berfungsi untuk memikat ikan agar berkumpul di suatu daerah penangkapan di lautan (Musbir, 2009; Dempster \& Taquet, 2004). Lihat gambar 1, contoh sistem rumpon di laut dangkal dan gambar 2, contoh rumpon di selatan samudera Hindia, untuk laut dalam.

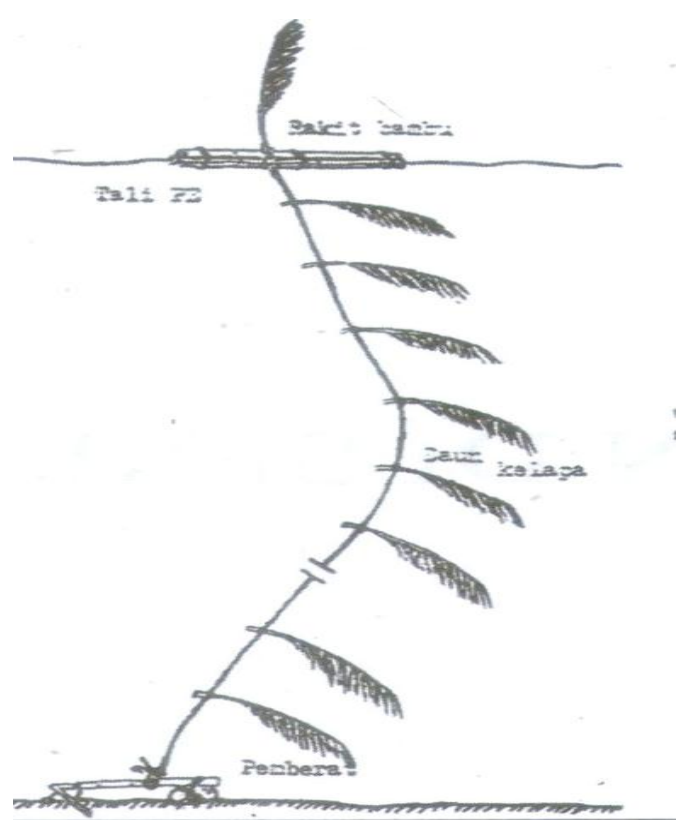

Gambar 1. Rumpon laut dangkal (Baskoro et al., 2011). Figure 1.Shallow water FAD (fish aggregating device) (Baskoro et al., 2011)

Adanya ikan di sekitar rumpon menciptakan suatu arena makan dan dimakan, dimulai dengan tumbuhnya bakteri dan mikroalga ketika rumpon dipasang (Baskoro et al., 2011). Hewan-hewan kecil akan menarik ikan-ikan pelagis kecil dan selanjutnya ikan-ikan pelagis besar akan memangsa ikan-ikan pelagis kecil. Rumpon juga memberikan tempat untuk berlindung bagi ikan, baik berlindung dari arus yang kuat maupun dari pemangsanya (Purbayanto et al., 2010; Musbir, 2009). Secara teknis konstruksi rumpon umumnya terdiri dari empat (4) bagian, pertama pengapung (buoy), kedua pemikat (attractor), ketiga tali pengapung (mooring line), dan terakhir adalah pemberat (jangkar). Karena definisi rumpon sebagai alat bantu pengumpulan ikan atau gerombolan ikan, maka terumbu karang buatan (artificial reef) dan keramba jaring apung (KJA) juga dapat dianggap sebagai rumpon (Baskoro et al., 2011).

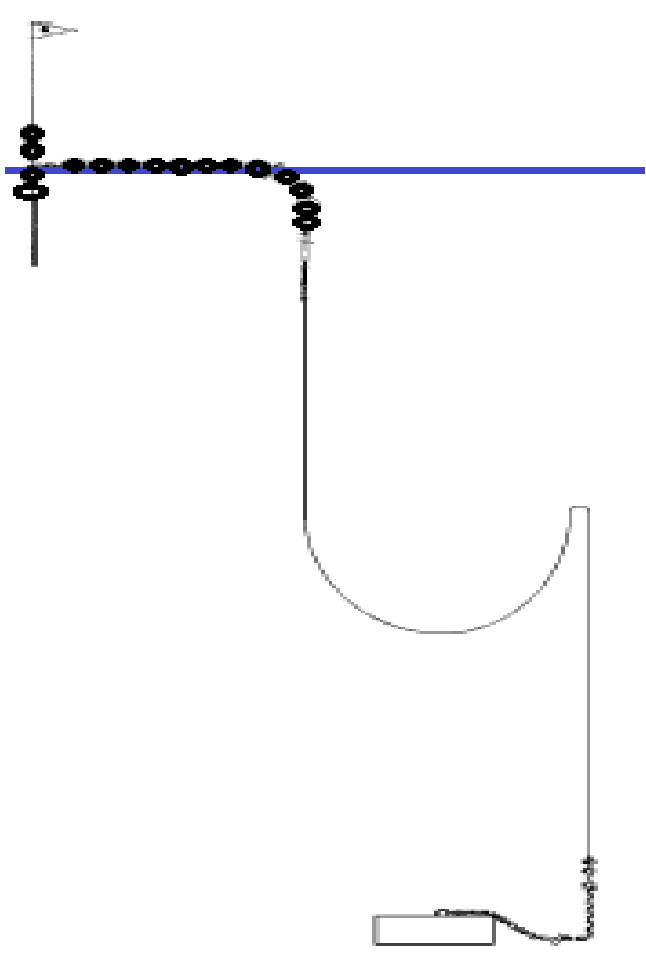

Gambar 2. Rumpon jenis rakit (raft) untuk laut dalam yang di jangkar (moored) (Gates et al., 1996)

Figure 2.The moored raft type of FAD for deep sea water (Gates et al, 1996)

Rumpon untuk penangkapan tuna di Samudera Atlantik menunjukkan relasi yang positif antara kelimpahan tuna dengan mikronekton dan salinitas yang rendah di sekitar pulau Martinique, Amerika Tengah (Doray et al., 2009). Lihat Gambar 3. Tuna yang bermigrasi secara temporer tidak tertarik dengan adanya FAD jika kondisi lingkungan dan kesuburan perairan tidak mendukungnya. Parameter yang diukur Doray et al. adalah suhu, salinitas, oksigen terlarut yang dihubungkan dengan kedalaman (depth), serta konsentrasi chlorophyll-a di permukaan laut. 


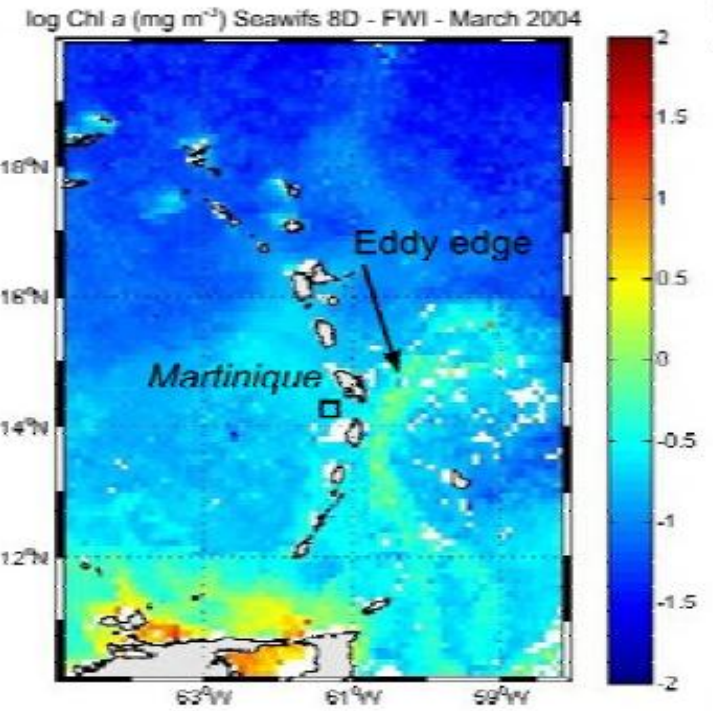

Gambar 3. Lokasi Pulau Martinique, Amerika Tengah dengan logaritmik Chlorophyll-A berdasarkan data satelit (Doray, 2009).

Figure 3.Martinique Island location, Middle America with logaritmic Chlorophyll-a based on satelite data

(Doray, 2009).

Di Indonesia, di laut Flores, Sulawesi Selatan, Musbir (2009) menggunakan parameter suhu, kecepatan arus, dan kelimpahan fitoplankton dibandingkan dengan hasil tangkapan kapal purse seine pada area rumpon. Lihat Gambar 4. Hasilnya menunjukkan korelasi positif antara jumlah hasil tangkapan dengan kelimpahan fitoplankton.

Lokasi Penelitian di Laut Flores Sulawesi Selatan

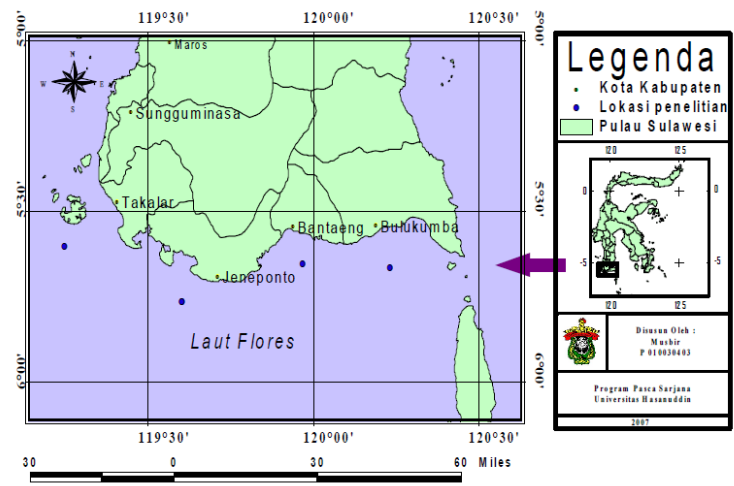

Gambar 4. Lokasi Penelitian di laut Flores Sulawesi Selatan, tentang hubungan parameter oseanografi dengan hasil tangkapan ikan di area sekitar rumpon (Musbir, 2009).

Figure 4.The research location in Flores sea south Sulawesi, about relationship of oceanography parameter with fish capture around $F A D$ (Musbir, 2009).
Komposisi hasil tangkapan adalah Ikan layang $24 \%$, Kembung 23\%, Tembang 21\%, Selar $13 \%$, Tongkol 9\%, lainnya 10\%. Musbir (2009) juga menyatakan bahwa pada kecepatan arus di atas $0,5 \mathrm{~m} /$ detik sulit ditemukan ikan pelagis kecil sekitar rumpon. Hal ini sejalan dengan sifat-sifat tingkah laku ikan yang mencari tempat berlindung (Purbayanto et al., 2010), namun jika arus terlalu kuat maka ikan akan pergi.

Teknologi observasi laut in-situ sudah berkembang dengan baik di dunia, bahkan di Indonesia. Indonesia dan Amerika Serikat telah menempatkan puluhan TAO buoy di Samudera Pasifik dan Hindia untuk memantau dan meneliti korelasi cuaca di dunia dengan suhu permukaan samudera (Pandoe \& Djamaluddin, 2009). Indonesia juga telah mengembangkan buoy untuk memantau tsunami dengan nama Ina-TEWS buoy. Lihat Gambar 5.

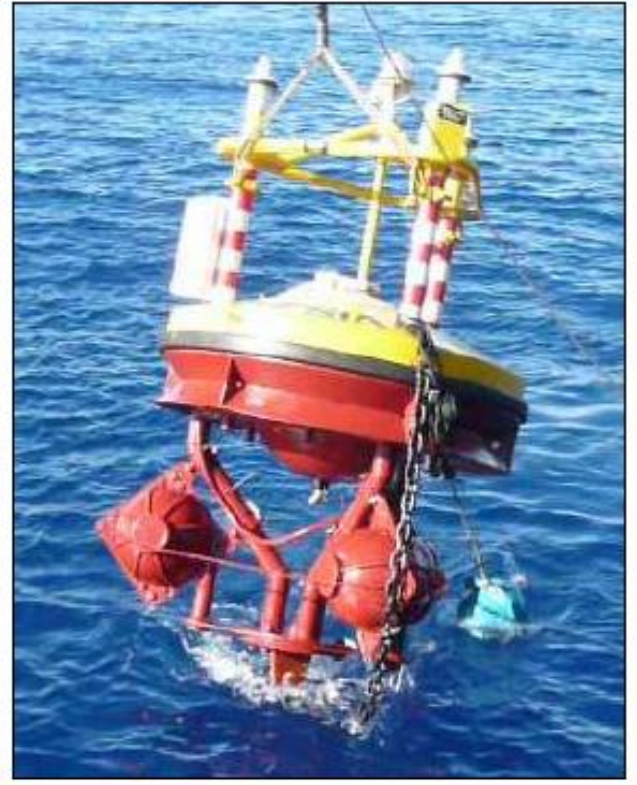

Gambar 5. Ina-TEWS buoy, alat pemantau tsunami insitu (Pandoe \& Djamaluddin, 2009).

Figure 5.The Ina-TEWS buoy, the in-situ tsunami monitoring tool (Pandoe \& Djamaluddin, 2009)

Untuk aplikasi pemantauan perairan laut secara insitu, juga telah dikembangkan INAGOOS-buoy dari Kementerian Kelautan dan Perikanan (KKP) yang bekerjasama dengan IPB tahun 2007-2009 (Mbay \& Rahmania, 2010). Kesulitan utama pemantauan in-situ dengan menggunakan buoy adalah vandalisme dan kegagalan rekayasa (bocor 
dan patah) yang dialami Ina-TEWS buoy dan INAGOOS buoy.

Belajar dari pengalaman-pengalaman tersebut di atas, telah dikembangkan buoy PLUTO, oleh Pusat Pengkajian dan Perekayasaan Teknologi Kelautan dan Perikanan (P3TKP) - Badan Litbang Kelautan dan Perikanan, KKP, pada tahun 2010 untuk pemantauan kualitas perairan secara in-situ di wilayah budidaya rumput laut di Wakatobi, Sulawesi Tenggara (Chandra, 2012). Lihat Gambar 6. Hasilnya berupa data menerus (continue) selama 7 bulan dengan parameter suhu, salinitas, oksigen terlarut (DO) dan tingkat keasaman $(\mathrm{pH})$. Lihat Gambar 7. Buoy PLUTO generasi pertama ini belum memiliki sistem telemetri, sehingga data harus diunggah secara manual memakai USB yang dikoneksikan ke laptop.

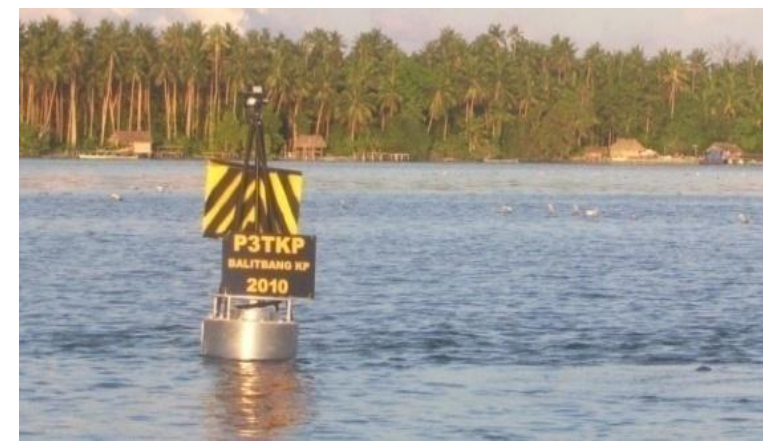

Gambar 6. Buoy PLUTO (Perairan Selalu Termonitor) di Wakatobi (Chandra, 2012).

Figure 6.Buoy PLUTO (stands for: Perairan selaLU termoniTOr) in Wakatobi (Chandra, 2012).

Informasi ilmiah tentang hubungan antara variabel oseanografi dengan keberadaan dan kelimpahan ikan di sekitar rumpon masih sangat terbatas (Musbir, 2009). Namun, diketahui secara umum bahwa faktor oseanografi dan kesuburan perairan pasti berpengaruh terhadap jumlah ikan di sekitar rumpon (Doray et al., 2008 dalam Musbir, 2009; Doray et al., 2009). Ketersediaan teknologi observasi in-situ dan sedikit inovasi dapat menjawab permasalahan dan berusaha dicarikan solusinya, mengenai kurangnya data oseanografi di sekitar rumpon yang dinyatakan Musbir (2009).

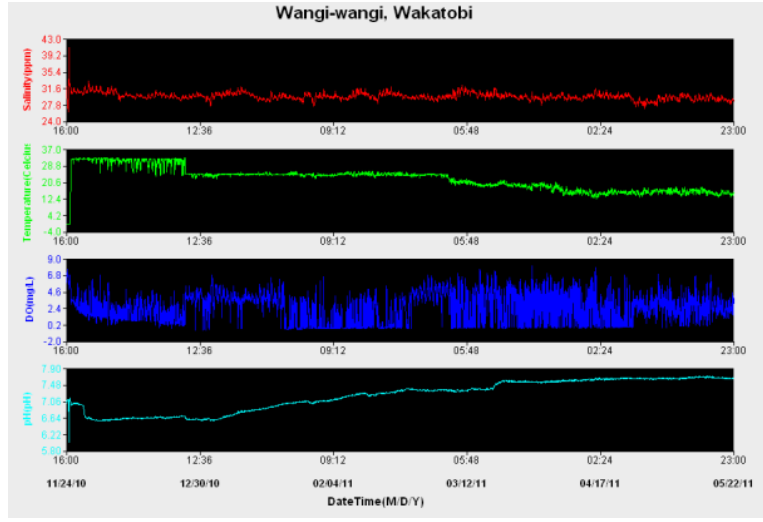

Gambar 7. Data suhu, salinitas, DO, dan pH hasil pencatatan in-situ dari buoy PLUTO di Wakatobi (Chandra, 2012).

Figure 7.Data temperature, salinity, $\mathrm{DO}$, and $\mathrm{pH}$ from in-situ measurement from buoy PLUTO in Wakatobi (Chandra, 2012).

Paper ini mencoba mengkaji/menilai (assesment) aspek teknologi observasi in-situ dengan memanfaatkan buoy untuk memahami relasi penangkapan ikan di sekitar rumpon (FAD) dengan parameter lingkungan perairan. Menurut Musbir (2009), masih jarang dilakukan dan mungkin belum pernah dilakukan, khususnya untuk pemantauan perairan sekitar rumpon dengan data secara menerus (continue).

\section{BAHAN DAN METODE}

Metode kajian dalam makalah ini adalah berupa hasil evaluasi implementasi perekayasaan buoy PLUTO pada tahun 2010 dan 2013, ditambahkan kajian referensi terkait, serta teknologi survey dan instrumentasi terkini.

Tahapan perancangan rekayasa (engineering process) disain sistem observasi in-situ untuk kawasan perairan sekitar rumpon adalah sebagai berikut:

1. Identifikasi masalah

2. Identifikasi kriteria dan batasan (constraint)

3. Solusi tukar pikiran kilat (brain-storming)

4. Eksplorasi tiap kemungkinan.

5. Memilih pendekatan

6. Membuat konsep/disain/prototipe.

Tahapan-tahapan di atas terus diulang selama proses desain, selanjutnya pada proses fabrikasi, sampai pada proses instalasi, demikian seterusnya 
sampai tercapai produk rekayasa (generasi satu, dua, dst) yang semakin baik dan sempurna.

\section{HASIL DAN PEMBAHASAN}

Pada tahun 2013, P3TKP - Balitbang KP, KKP telah berhasil menyempurnakan buoy PLUTO, dari generasi pertama (2010) yang belum memiliki sistem telemetri, menjadi punya sistem telemetri. Buoy PLUTO ini ditempatkan di Pekalongan (Jawa Tengah) dan Wakatobi (Sulawesi Tenggara). Sistem telemetrinya mampu mengukur parameter suhu, salinitas, oksigen terlarut (DO), dan derajat keasaman $(\mathrm{pH})$. Hasil sistem telemetri inovasi ini dapat dilihat pada Gambar 8.

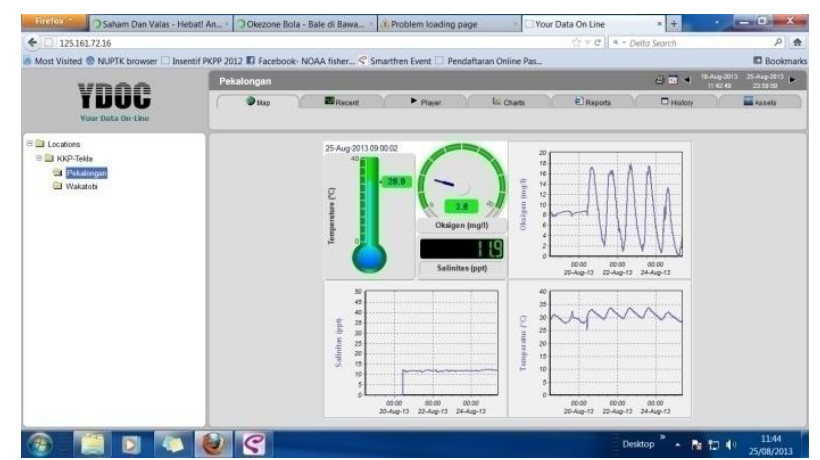

Gambar 8. Data suhu, salinitas, DO, hasil pencatatan insitu di Pekalongan, dengan sistem web (on-line).

Figure 8. Data of temperature, salinity, DO, the result of recording in Pekalongan, by using web system (on-line)

\subsection{Identifikasi Masalah}

Identifikasi masalah dari pengukuran kualitas perairan di sekitar rumpon adalah agar dapat diperoleh data secara menerus, adalah biaya operasional kapal yang mahal dan waktu melaut yang tergantung cuaca. Selain itu, pengukuran memakai penginderaan jauh terbatas hanya suhu permukaan laut (SPL), salinitas dan klorofil-a yang juga dari permukaan laut saja, bukan di kolom air (Simbolon et al., 2013; Minnet, 2009; McClain, 2009; Lagerloef, 2009). Selanjutnya, sering juga terjadi perbedaan hasil pengukuran. Sebagai contoh, perbedaan hasil pengukuran suhu permukaan laut di lapangan (in-situ) dan ex-situ (citra satelit) di perairan Mentawai rata-rata sebesar $1{ }^{\circ} \mathrm{C}$ pada bulan Maret dan Mei 2007 (Simbolon et al., 2013). Perbedaan ini umumnya disebabkan karena pengaruh atmosfer seperti uap air dan awan. Pengaruh awan dapat menurunkan suhu pengukuran SPL (suhu permukaan laut) sampai $1,5^{\circ} \mathrm{C}$ dibandingkan suhu pengukuran in-situ (Gaol, 2003 dalam Simbolon et al., 2013). Telah diketahui secara umum, bahwa proses pengambilan data oleh sensor penginderaan jauh seperti citra satelit tidak akan mungkin lepas dari pengaruh awan. Semakin banyak kandungan awan, maka akan semakin kecil wilayah yang dapat dideteksi kandungan klorofil dan sebaran suhunya, demikian pula sebaliknya (Simbolon et al., 2013). Dengan penjelasan di atas, maka pengukuran insitu adalah mutlak diperlukan agar hasil penelitian dapat lebih presisi dan berkualitas. Suhu yang dideteksi oleh satelit adalah suhu yang berasal dari radiasi balik pada permukaan laut (skin sea surface temperatur), sedangkan suhu aktual kolom air adalah suhu pada lapisan beberapa centimeter di bawah permukaan laut (bulk sea surface temperature).

\subsection{Identifikasi Kriteria dan Batasan}

Untuk menyelesaikan masalah di atas adalah dengan memakai teknologi buoy, dengan kriteria sebagai berikut:

1. Memiliki sensor suhu, salinitas, DO, dan klorofil-a.

2. Memiliki pengukur arus.

3. Dapat mengirimkan data secara telemetri (on-line).

4. Disain buoy harus mobile.

5. Instalasi mudah dan tidak perlu kapal khusus.

6. Minimal beroperasi selama 1 tahun, menyesuaikan angin monsoon, yang membawa fenomena upwelling dan downwelling pada bulan Juni-Agustus dan Desember-Februari (Gordon, 2005).

\subsection{Solusi Tukar Pikiran Kilat}

Alternatif disain buoy yang bisa dipakai adalah buoy Ina-TEWS, buoy INAGOOS, dan buoy PLUTO. Dari hasil yang sudah diperoleh berupa uji lapangan dan kriteria untuk solusi masalah, maka buoy PLUTO lebih teruji, lebih mobile, dan tidak memerlukan kapal khusus untuk instalasinya, dibanding yang lain (Chandra, 2012; Mbay \& Rahmania, 2010; Pandoe \& Djamaluddin, 2009). Dengan demikian, teknologi pemantauan perairan secara in-situ dengan menggunakan buoy PLUTO yang dikembangkan P3TKP, Balitbang KP-KKP adalah solusi tukar pikiran kilat untuk masalah yang teridentifikasi diatas. 


\subsection{Eksplorasi Tiap Kemungkinan}

Pemakaian rumpon di Indonesia sudah begitu banyak dan umum di kalangan nelayan. Berdasarkan pengalaman penulis, nelayan di Pelabuhanratu - Jawa Barat, Pekalongan - Jawa Tengah, Bitung - Sulawesi Utara, Kendari dan Wakatobi - Sulawesi Tenggara, Makassar Sulawesi Selatan, dan Ternate - Maluku Utara sudah sering menggunakan rumpon untuk memudahkan penangkapan ikan. Di Palabuhanratu, pembuatan jangkar sampai bersifat massal (lihat Gambar 9). Di Pekalongan - Jawa Tengah, rumpon memiliki pengapung yang besar dan dibawa dengan kapal ukuran 30 GT, lihat Gambar 10. Umumnya disain rumpon dapat dilihat seperti pada Gambar 1.

Secara teknis, maka rumpon dapat terbagi 4 bagian. Pertama adalah jangkar (seperti Gambar 9), kedua pengapung (seperti Gambar 10), ketiga tali atau rantai (mooring), dan terakhir adalah pemikat (attractor). Keempat bagian ini tidak dapat dipisahkan karena merupakan satu kesatuan sistem rumpon.

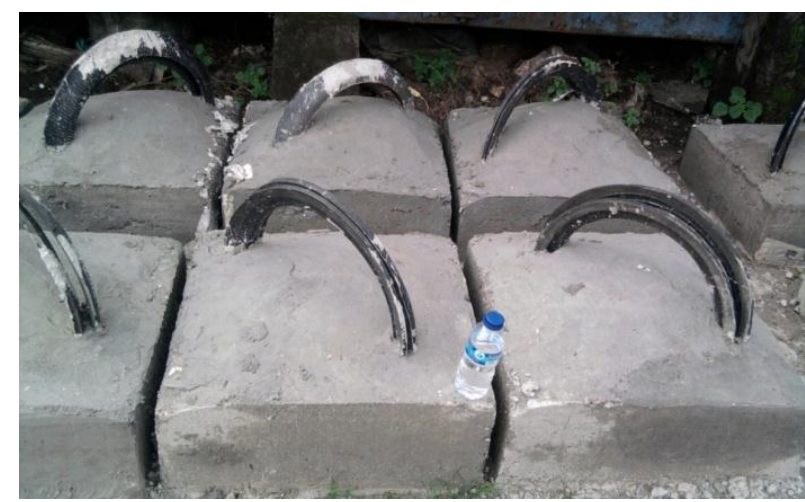

Gambar 9. Ukuran jangkar rumpon, dibandingkan botol aqua, di Palabuhanratu tahun 2013.

Figure 9.The achor size for FAD, compared with Aqua bottle, at Palabuhanratu, 2013.

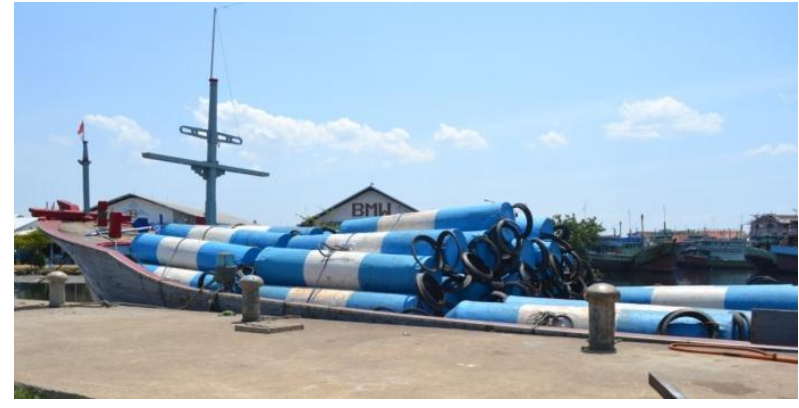

Gambar 10. Ukuran pelampung rumpon, diatas kapal 30 GT di Pekalongan, Jawa Tengah.

Figure 10.The size of floater for FAD, onboard 30 GT fishing vessel in Pekalongan.

Josse et al. (2000) mempublikasikan hasil penelitian tentang sebaran ikan di daerah sekitar rumpon di wilayah Perancis Polinesia, terdapat 3 bagian ikan bedasarkan sebaran kedalaman. Lihat gambar 11. Penelitian ini juga menunjukkan bahwa observasi in-situ di kolom air perlu dilakukan untuk meningkatkan pengetahuan tingkah laku ikan. Hal ini akhirnya akan meningkatkan efisiensi penangkapan ikan, seperti terbukti hasil penelitian Josse et al. (2000) dengan hasil tangkapan nelayan di Tahiti.

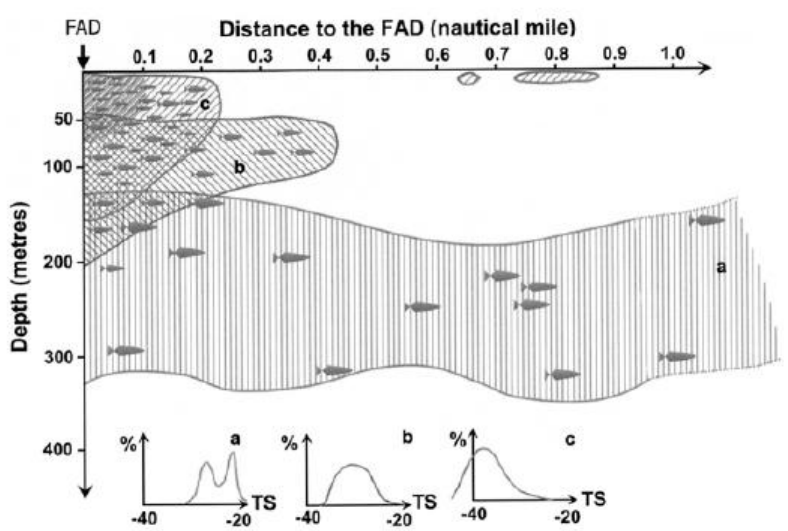

Gambar 11. Sebaran ikan berdasarkan kedalaman, menggunakan echosounder SIMRAD EK500. Tipologi penggerombolan ikan di sekitar rumpon di Tahiti, (a) "deep scaterred fish", (b) "intermediate scaterred fish",

(c) "shallow schooling fish" (Josse et al., 2000).

Figure 11.The fishes distribution based on depth, by using SIMRAD EK500 echosounder. Tipology of fish aggregation around FAD in Tahiti, (a)deep scaterred

fish, (b)intermediate scaterred fish, (c) shallow schooling fish (Josse et al. , 2000). 


\subsection{Pemilihan Pendekatan dan Disain Konsep/Prototipe}

Pembuatan dan desain alat observasi in-situ perairan di sekitar rumpon memakai pendekatan adaptif dengan penguasaan teknologi dan kebiasaan nelayan. Pembuatan buoy PLUTO tidak mengalami perubahan besar (significant), karena hanya perlu dikait atau diikat dengan rumpon dari nelayan pada tali tambatannya (mooring line). Lihat Gambar 12.

Parameter-parameter perairan yang perlu untuk diukur terkait dengan rumpon adalah suhu (Gordon, 2005; Doray et al., 2009; Musbir, 2009; Simbolon et al., 2013), arus (Gordon, 2005; Musbir, 2009), salinitas (Gordon, 2005; Doray et al., 2009), oksigen terlarut (DO) (Sidabutar, 2012; Doray et al., 2009), dan klorofil a (Sidabutar, 2012; Doray et al., 2009; Simbolon et al., 2013).

Arus laut juga diketahui mempengaruhi kelimpahan ikan di area rumpon. Ketika kecepatan arus semakin kuat akan mengharuskan ikan menggunakan energi yang besar untuk tetap berada di rumpon.

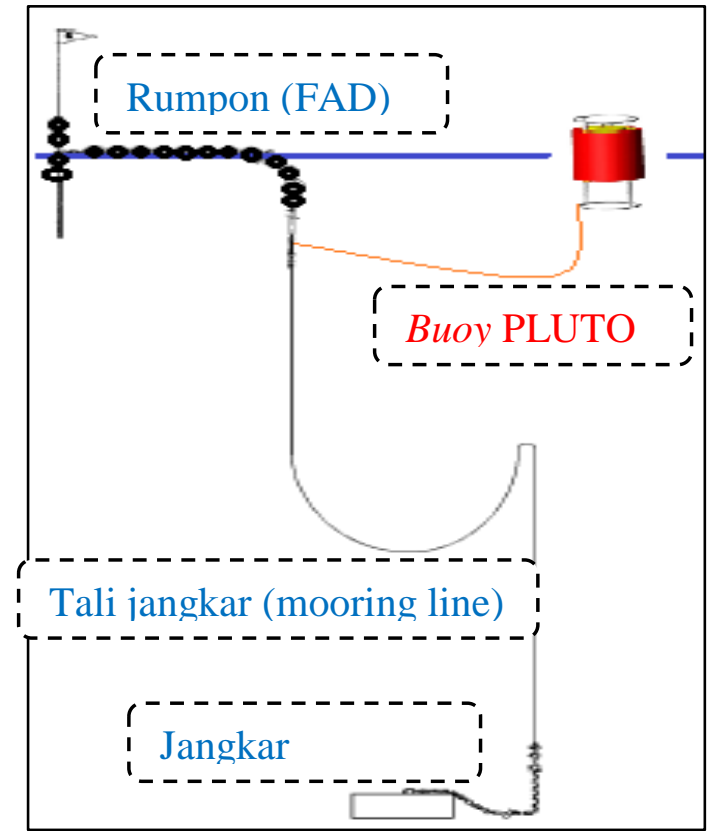

Gambar 12. Konsep teknis pengukuran parameter perairan in-situ di area rumpon, dengan memanfaatkan buoy PLUTO.

Figure 12. The technical concept for in-situ water parameter measurement around rumpon area, by using buoy PLUTO.
Oleh karena itu, penangkapan ikan akan lebih efisien pada kondisi arus lemah. Pada kecepatan di atas $0,5 \mathrm{~m} /$ detik sulit ditemukan ikan pelagis kecil di sekitar rumpon (Musbir, 2009). Selain itu, arus lintas Indonesia (ITF, Indonesian Throuhflow) termasuk kencang, khususnya yang melintasi selat Makassar (Gordon, 2005).

Secara konseptual teknis, pengukuran parameterparameter perairan di area rumpon dapat menggunakan buoy PLUTO yang dikaitkan dengan rumpon, seperti pada Gambar 12. Semua sensor dan alat untuk pengukuran parameter-parameter penting, seperti suhu, salinitas, DO, arus, dan klorofil-a dapat di tempatkan pada buoy PLUTO. Jika diperlukan, untuk akurasi yang lebih baik, dapat ditambahkan dengan sensor cuaca seperti angin, curah hujan dan suhu udara. Pengiriman data dapat dilakukan dengan menggunakan jaringan telepon GSM (contoh Simpati, XL, atau Mentari), atau jaringan satelit (Iridium). Pengukuran dapat dilakukan setiap 5 menit, atau 10 menit, atau 15 menit sesuai dengan kebutuhan.

Dari hasil instalasi buoy PLUTO di Pekalongan tahun 2013, menunjukkan hasil yang bagus dan memuaskan. Data yang diperoleh secara telemetri menunjukkan penjelasan kenapa di kolam Pelabuhan Perikanan Nusantara (PPN) Pekalongan tidak ada ikan yang dapat hidup. Lihat Gambar 13.

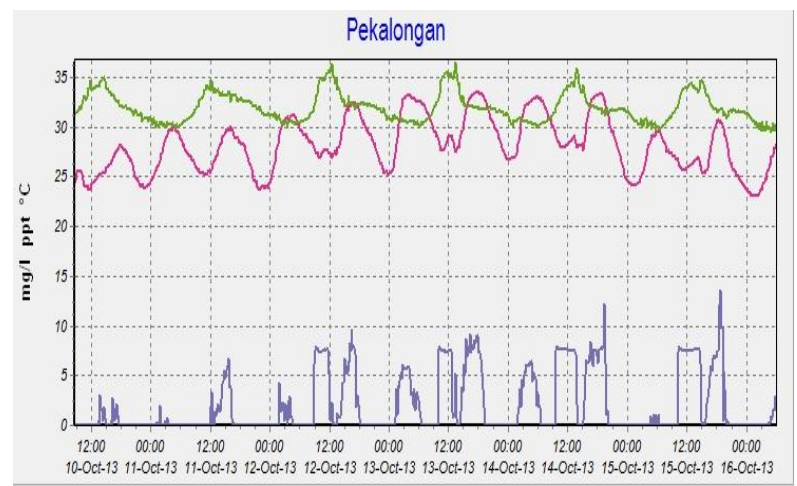

Gambar 13. Parameter DO (warna biru), parameter salinitas (warna jingga), parameter suhu (warna hijau) dari telemetri buoy PLUTO.

Figure 13. DO parameter (blue color), salinity parameter (violet color), temperature parameter (green color) from buoy PLUTO's telemetry. 
Pengukuran menunjukkan nilai kandungan oksigen terlarut (DO) adalah nol (0), dan salinitas fluktuasinya cukup tinggi. Nilai dua parameter ini berubah saat terjadi pasang air laut, sekitar jam 12 sampai 16 di siang hari.

Data dari buoy PLUTO di Wakatobi juga menunjukkan hasil yang bagus, dimana nilai parameter-parameter perairan yang diukur relatif sama dengan yang dilakukan Tadjuddah et al., (2013). Nilai parameter temperatur sekitar 24-31 ${ }^{\circ} \mathrm{C}$, salinitas $30-33 \mathrm{ppt}$, DO > 3,5 ppm, dan nilai $\mathrm{pH} 7,8-8$.

\section{KESIMPULAN DAN SARAN}

\section{Kesimpulan}

Dari hasil kajian dan perekayasaan yang sudah dilakukan, maka dapat disimpulkan hasil sebagai berikut:

a. Pengukuran paramater-parameter oseanografi perairan sekitar rumpon perlu dilakukan untuk meningkatakan efisiensi penangkapan ikan berdasarkan pola tingkah laku ikan yang menyesuaikan parameter lingkungan perairan.

b. Parameter yang dapat diukur antara lain suhu, salinitas, arus, DO, $\mathrm{pH}$ dan kesuburan perairan (klorofil a). Serta dapat ditambahkan sensor cuaca jika dibutuhkan.

c. Teknologi buoy PLUTO adalah pilihan yang positif untuk aplikasi observasi insitu perairan sekitar rumpon.

\section{Saran}

Saran atau rekomendasi yang dapat diberikan adalah, perlunya uji implementasi buoy PLUTO yang dapat dilakukan pada tahun 2014 dan hasilnya dapat dipakai pada tahun 2015. Dukungan institusi dan kerjasama dengan nelayan sangat menentukan keberlanjutan pemanfaatan buoy PLUTO ini.

\section{DAFTAR PUSTAKA}

Baskoro, MS, Taurusman AA, \& Sudirman. (2011). Tingkah laku ikan, hubungannya dengan ilmu dan teknologi perikanan tangkap. Bandung: CV. Luubuk Agung.
Chandra, H. (2012). Perekayasaan buoy pluto untuk memantau kualitas perairan budidaya rumput laut di Kabupaten Wakatobi, Sulawesi Tenggara. Jurnal Kelautan Nasional, 7(3), 166-174.

Dempster, T., \& Taquet, M. (2004). Fish aggregating device (FAD) research: gaps in current knowledge and future directions for ecological studies. Reviews in Fish Biology and Fisheries, 14(1), 21-42.

Gates, P., Cusack, P., \& Watt, P. (1996). South Pacific Commision fish aggregating device (fad) manual. Volume II, rigging deepwater fad moorings. Copyright South Pacific Commision 1996, Noumea, New Caledonia.

Doray, M., Petitgas, P., Nelson L., Mahévas S., Josse E., \& Reynal L. (2009). The Influence of the environment on the variability of monthly tuna biomass aroung a moored, fish aggregating device. ICES Journal of Marine Science, 66(6): 14101416.

Gordon, A. L. (2005). Oceanography of the Indonesian seas and their throughflow. Oceanography, 18(4), 14-27.

Josse, E., Dagorn, L., \& Bertrand, A. (2000). Typology and behaviour of tuna aggregations around fish agregating devices from acoustic surveys in French Polynesia. Aquatic Living Resources Journal, 13, 183-192.

Lagerloef, GSE. (2009). Satellite remote sensing: salinity measurement. In J. H. Steele, S. A. Thorpe, \& K. K. Turekian (Eds.), Measurement Techniques, Platforms and Sensors. A derivative of encyclopedia of ocean sciences $\left(2^{\text {nd }}\right.$ ed.). Academic Press, Elsevier Ltd.

Mbay, LON., \& Rahmania, R. (2010). Pembuatan buoy pantai untuk mendukung kegiatan perikanan budidaya di Kepulauan Seribu. Jurnal Kelautan Nasional, 5(3), 175-187.

McClain, CR. (2009). Satellite Remote Sensing: Ocean Colour. In J. H. Steele, S. A. Thorpe, \& K. K. Turekian (Eds.), Measurement Techniques, Platforms and Sensors. A derivative of encyclopedia of ocean sciences $\left(2^{\text {nd }}\right.$ ed.). Academic Press, Elsevier Ltd.

Minnett, PJ. (2009). Satellite remote sensing of sea surface temperatures. In J. H. Steele, S. A. Thorpe, \& K. K. Turekian (Eds.), 
Measurement Techniques, Platforms and Sensors. A derivative of encyclopedia of ocean sciences $\left(2^{\text {nd }}\right.$ ed.). Academic Press, Elsevier Ltd.

Musbir. (2009). Hubungan antara variabel oseanografi dengan penangkapan ikan pelagis pada area rumpon di perairan Laut Flores, Sulawesi Selatan. Prosiding Seminar ISOI 2009.

Pandoe, W., \& Djamaluddin, R. (2009). The Indonesian Tsunami Buoy Development Program. Prosiding Seminar ISOI 2009.

Purbayanto, A., Riyanto, M., \& Fitri, ADP. (2010). Fisiologi dan tingkah laku ikan pada perikanan tangkap. Bogor, Indonesia: PT. Penerbit IPB Press, Kampus IPB Taman Kencana.

Sidabutar, T. (2012). Kajian eutrofikasi dan "harmful algal blooms" di Perairan Teluk Jakarta. Prosiding Seminar Nasional Perikanan Indonesia 13-14 November 2012, STP, Jakarta. Hal 481-490.

Simbolon, D., Silvia, \& Wahyuningrum, PI. (2013). Pendugaan thermal front dan upwelling sebagai indikator daerah potensial penangkapan ikan di perairan Mentawai. Jurnal Teknologi dan Manajemen Perikanan Laut, 4(1), 85-95. Fakultas Perikanan dan Ilmu Kelautan, Institut Pertanian Bogor.

Tadjuddah, M., Wiryawan, B., Purbayanto, A., \& Wiyono, ES. (2013). Parameter biologi ikan kerapu (epinephelus sp.) Hasil tangkapan di perairan Taman Nasional Wakatobi, Sulawesi Tenggara Indonesia. Jurnal Teknologi dan Manajemen Perikanan Laut, 4 (1), 11-21. 